\title{
Medroxyprogesterone Acetate Prevention of Cervical Cancer through Progesterone Receptor in a Human Papillomavirus Transgenic Mouse Model
}

\author{
Seunghan Baik, Fabiola F. Mehta, and Sang-Hyuk Chung
}

From the Center for Nuclear Receptors and Cell Signaling, Department of Biology and Biochemistry, University of Houston, Houston, Texas

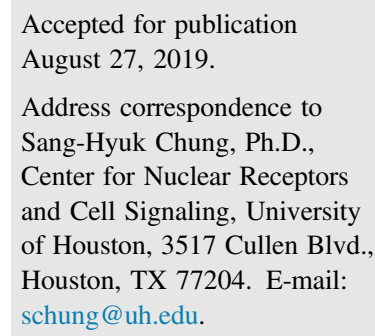

Address correspondence to Sang-Hyuk Chung, Ph.D., Center for Nuclear Receptors and Cell Signaling, University of Houston, 3517 Cullen Blvd., Houston, TX 77204. E-mail: schung@uh.edu.

\begin{abstract}
Cervical dysplastic lesions called cervical intraepithelial neoplasias (CINs) need be treated to prevent cervical cancer. Currently available surgical procedures are effective, but the development of noninvasive treatment is warranted. In human papillomavirus transgenic mice engineered to express human papillomavirus type $16 \mathrm{E} 6$ and $\mathrm{E} 7$, short-term treatment with $17 \beta$-estradiol induces CINs that progress to cervical cancer if the treatment is continued. In the present study, this mouse model was used to determine whether medroxyprogesterone acetate (MPA), a progestin drug, is chemopreventive. Human papillomavirus transgenic mice bearing CIN lesions were treated with MPA plus $17 \beta$-estradiol. Unlike control mice treated with $17 \beta$-estradiol alone, cervical cancer was absent in the MPA-treated mice. This observation suggests that MPA prevented CIN from progressing to invasive cancer. MPA was associated with inhibited cell proliferation and the promotion of apoptosis in CIN lesions. Confirming the role of the progesterone receptor, the preventive effect of MPA was absent in human papillomavirus transgenic mice in which the expression of progesterone receptor was genetically ablated. These results suggest that MPA is efficient in treating progesterone receptor-positive CIN lesions. These findings provide the basis for a biomarker-driven clinical trial of the secondary prevention of cervical cancer. (Am J Pathol 2019, 189: 2459-2468; https://doi.org/10.1016/j.ajpath.2019.08.013)
\end{abstract}

High-risk human papillomavirus (HPV) infects the stratified squamous epithelium and may induce cervical cancer, ${ }^{1}$ the third most common and third most deadly cancer in women worldwide. ${ }^{2}$ Although the prevalence of cervical intraepithelial neoplasias (CINs), precancerous lesions, is much higher than that of cervical cancer, its impact on women's health has not been fully appreciated. The negative impact of CINs on the psychological and psychosocial wellness of women is as great as that of cervical cancer. ${ }^{3-6}$ This prevalent gynecologic cancer can be prevented by HPV vaccination and screening (ie, cervical cytology and HPV testing). Current prophylactic HPV vaccines are effective in inhibiting HPV infection and thereby preventing CIN. ${ }^{7}$ The Papanicolaou smear allows early detection of CINs, which can be surgically removed by procedures such as the loop electrosurgical excision procedure or cold knife cone biopsy. These preventive methods, however, are not readily available to women in developing countries or to those of low socioeconomic status in developed countries due to the lack of infrastructure and/or high cost. In fact, the global burden of cervical cancer was unchanged from 2012 to 2018. . $^{2,8}$

Persistent HPV infection promotes the development of high-grade CIN3, with a 3-year risk of $14 \%$ to $40 \%$ depending on HPV type. ${ }^{9}$ Although CIN3 is recommended to be treated, up to $70 \%$ of cases regress without any treatment. ${ }^{10}$ These observations suggest that HPV infection is not by itself sufficient to drive high-grade cervical cancer and that other cofactors are required for cervical cancer. The long-term use of oral contraceptives and multiple full-term pregnancies increase the risk for cervical cancer in HPVinfected women, implicating the female sex hormones,

Supported in part by NIH grant R01 CA188646 (S.-H.C.), Cancer Prevention and Research Institute of Texas grant RP180275 (S.-H.C.), and University of Houston Large Core Equipment grant 1HOU44 (S.-H.C.).

Disclosures: None declared. 
Table 1 Antibodies and Conditions for IHC

\begin{tabular}{llllll}
\hline Antibody & Manufacturer & Cat no. & Clone no. & Blocking buffer & Antibody dilution \\
\hline BrdU & EMD Biosciences, San Diego, CA & NA61 & Mobu-1 & $5 \%$ goat serum & $1: 50$ \\
ER $\alpha$ & Immunotech, Marseille, France & IM1545 & 1D5 & $5 \%$ goat serum & $1: 100$ \\
Ki-67 & Thermo Scientific, Fremont, CA & RM-9106 & SP6 & $5 \%$ goat serum & $1: 100$ \\
MCM7 ${ }^{*}$ & Lab Vision, Fremont, CA & MS-862 & 47DC141 & $0.5 \%$ skim milk $+5 \%$ goat serum & $1: 200$ \\
PR & Sigma-Aldrich, St. Louis, M0 & SAB5500165 & SP2 & $5 \%$ goat serum & $1: 1000$ \\
p16 ${ }^{\text {Ink4a }}$ & Rockland Immunochemicals, Limerick, PA & $600-401-A J 9$ & Polyclonal & $5 \%$ goat serum & $1: 200$ \\
\hline
\end{tabular}

*Discontinued.

BrdU, bromodeoxyuridine; ER, estrogen receptor; MCM, minichromosome maintenance complex component; PR, progesterone receptor.

estrogen and progesterone. ${ }^{11,12}$ These hormones function through estrogen receptor (ER)- $\alpha$ and progesterone receptor (PR), which are ligand-dependent transcription factors of the nuclear receptor superfamily. ${ }^{13}$ The risk for high-grade CIN is 2.3-fold higher in women who have been exposed in utero to diethylstilbestrol, a synthetic estrogen. ${ }^{14}$ The use of an aromatase inhibitor that blocks estrogen biosynthesis has been associated with a lower risk for cervical cancer. ${ }^{15}$ These observations suggest that estrogen promotes cervical cancer. The role of progesterone in cervical cancer, however, is much less explored. One epidemiologic study showed that the use of medroxyprogesterone acetate (MPA), a synthetic progesterone, was associated with a reduced risk for cervical cancer in HPV-infected women. ${ }^{16}$ Although it needs to be verified in independent studies, this observation suggests that progesterone inhibits cervical carcinogenesis.

Virus-encoded E6 and E7 are the major drivers of HPVinduced cancers including cervical cancer. K14-HPV16 transgenic mice that express all HPV16 early genes, including E6 and E7, do not develop cervical cancer unless chronically treated with the most potent estrogen, $17 \beta$-estradiol $\left(\mathrm{E}_{2}\right) .{ }^{17}$ It is consistent with the premise that HPV is not sufficient and that estrogen promotes cervical cancer. $\mathrm{E}_{2}$ also promotes cervical cancer in $K 14 E 6 / K 14 E 7$ double transgenic mice that are engineered to express only HPV16 E6 and E7. ${ }^{18,19}$ Similar to cervical carcinogenesis in women, murine cervical neoplastic disease develops in the transformation zone through multiple stages, starting from CIN and culminating in invasive cancer. ${ }^{19}$ Cervical cancer biomarkers such as p $16^{\mathrm{INK} 4 \mathrm{a}}$ and cyclin $\mathrm{E}$ are expressed, and the K14E6/K14E7 model has been used to identify minichromosome maintenance complex component 7 as a novel cervical cancer biomarker. $^{20,21}$ In cervical cancer clinical samples, ER $\alpha$ is expressed in the cancer stroma but not in the cancer epithelium. ${ }^{22}$ In the HPV transgenic mouse model, stromal ER $\alpha$, but not epithelial ER $\alpha$, mainly mediates the oncogenic activity of $\mathrm{E}_{2}{ }^{23,24}$ These observations validate the relevance of the K14E6/K14E7 mouse model to human cervical cancer. Using this model system, it has been demonstrated that MPA promotes regression of cervical cancer. ${ }^{25}$ Here, the same mouse

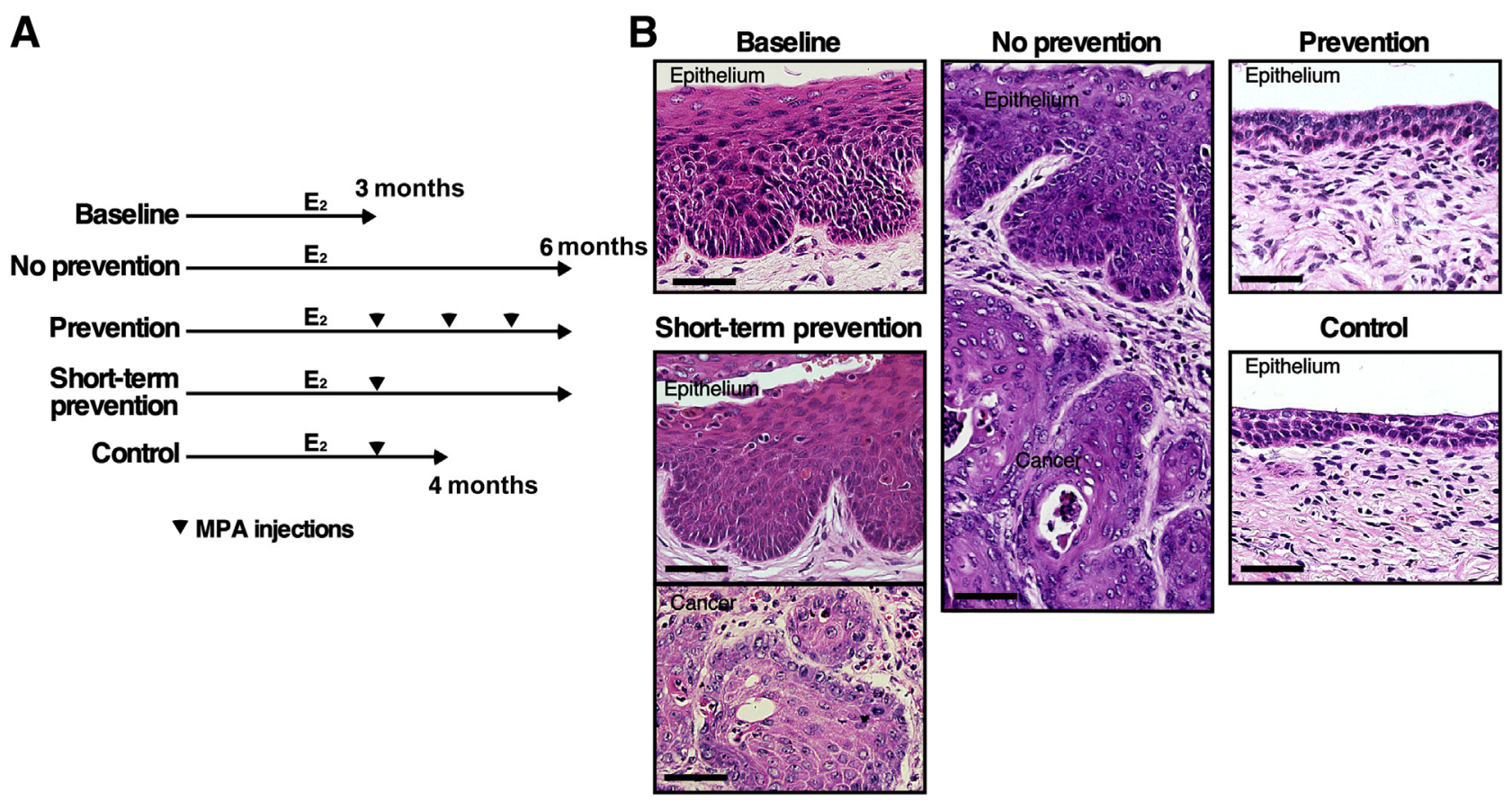

Figure 1 Medroxyprogesterone acetate (MPA) prevents the onset of cervical cancer. A: Treatment regimens for the chemopreventive approach are depicted. All mice were treated with $E_{2}$ (estrogen) until end points $(3,4$, or 6 months). Arrowheads indicate monthly injections with MPA. B: MPA induces hypoplasia in the cervix. Shown are high-magnification images of representative hematoxylin and eosin-stained cervical tissues. Scale bar $=50 \mu \mathrm{m}$. 
Table 2 Summary of Worst Diseases of the Cervix in HPVtg Mice

\begin{tabular}{|c|c|c|c|c|c|c|c|}
\hline \multirow[b]{2}{*}{ Group } & \multirow[b]{2}{*}{ Group size, $n$} & \multirow[b]{2}{*}{ No disease, $n$} & \multicolumn{3}{|c|}{ Dysplasia only, $n$} & \multirow[b]{2}{*}{ Cancer and dysplasia, $n$} & \multirow[b]{2}{*}{ Cancer incidence, $\%$} \\
\hline & & & CIN1 & CIN2 & CIN3 & & \\
\hline Baseline & 7 & 0 & 4 & 3 & 0 & 0 & 0 \\
\hline Prevention & 6 & 5 & 1 & 0 & 0 & 0 & 0 \\
\hline Short-term prevention & 9 & 0 & 2 & 4 & 0 & 3 & 33.3 \\
\hline Control & 10 & 8 & 0 & 2 & 0 & 0 & 0 \\
\hline
\end{tabular}

For Wilcoxon rank sum test, each lesion was given following arbitrary score: no disease $=1$; $\operatorname{CIN} 1=2 ;$ CIN2 $=3$; $\operatorname{CIN} 3=4$; and cancer $=5$.

${ }^{*} P<0.05$ versus the other groups (Fisher exact test).

CIN, cervical intraepithelial neoplasia.

model was used to determine whether MPA is chemopreventive. We show that MPA prevents CIN from progressing to invasive cancer in a PR-dependent manner. Our results suggest that MPA is effective in preventing the transition from PR-positive CIN to cervical cancer.

\section{Materials and Methods}

\section{Mice}

All mouse types used in this study have been previously described. K14E6/K14E7 double-transgenic mice were generated by crossing K14E7 [FVB-Tg(KRT14-HPV16E7)2304Plam] hemizygotes and K14E6 [FVB-Tg(KRT14-HPV16E6)5737Plam] homozygotes. ${ }^{26,27}$ They are referred to as HPVtg hereafter. Mice harboring the $P g r$-null allele were generated by mating $P g r^{\mathrm{f} / \mathrm{f}}$ (B6; 129S4; 129S7-Pgr ${ }^{\mathrm{tm} 4.1 \mathrm{Lyd}}$ ) conditional knockout with sex-determining region Y-box 2 Cre recombinase [B6; CBA- $\mathrm{Tg}(\mathrm{Sox} 2-\mathrm{cre}) 1 \mathrm{Amc}]$ transgenic mice, which allows germline deletion of floxed alleles. ${ }^{28,29}$ $\mathrm{HPVtg} / \mathrm{Pgr}^{+/-}$and $\mathrm{HPVtg} / \mathrm{Pgr}^{-1-}$ mice were generated by crossing $\mathrm{K} 14 \mathrm{E} 7 / \mathrm{Pgr}^{-1-}$ males and $\mathrm{K14E6/ \textrm {Pgr } ^ { + / - }}$ females. All mice were genotyped by PCR using genomic DNA isolated from tail biopsies. All procedures were approved by the University of Houston Institutional Animal Care and Use Committee.

\section{Drug Treatments}

For long-term $\mathrm{E}_{2}$ treatment, drug pellets that slowly release $\mathrm{E}_{2}(0.05 \mathrm{mg} / 60$ days; catalog number SE-121; Innovative Research of America, Sarasota, FL) were used. Slow-release drug tablets were inserted subcutaneously under the dorsal skin every 60 days starting at 4 to 6 weeks of age. Medroxyprogesterone acetate injectable suspension (product UPC 00359762453716; Greenstone LLC, Peapack, NJ) was mixed with $4 \mathrm{~mL}$ of phosphate-buffered saline to make $30 \mathrm{mg} / \mathrm{mL}$ stock suspension. Mice were injected i.p. with $0.15 \mathrm{~mL}$ of the diluted suspension, which delivers $4.5 \mathrm{mg}$ of MPA over a month. These $\mathrm{E}_{2}$ and MPA doses were calibrated in previous studies. ${ }^{19,25}$ Some mice were injected i.p. with $0.3 \mathrm{~mL}$ of $12.5 \mathrm{mg} / \mathrm{mL}$ bromodeoxyuridine (BrdU) 1 hour before euthanasia.

\section{Tissue Processing and Histopathologic Analysis}

Mouse female reproductive tracts were harvested, fixed in 4\% paraformaldehyde, and embedded in paraffin as previously described. ${ }^{19}$ The tissues were serially sectioned at 5 $\mu \mathrm{m}$ thickness throughout the cervix. Hematoxylin (catalog number 6765015; Thermo Fisher Scientific, Fremont, CA) and eosin (catalog number E4382; Sigma-Aldrich, St. Louis, MO) solutions were made according to the manufacturers' recommendations. For histopathologic analyses, every tenth slide was stained with hematoxylin and eosin. The worst neoplastic disease was determined as previously described. ${ }^{19}$ Criteria for diagnosis were the thickness of basal-like epithelial cell layer, nuclear atypia with enlarged nucleus, and stroma invasion. A mouse typically had multiple neoplastic disease states, and the worst disease state was assigned to each mouse. For Alcian blue staining, paraffin sections were deparaffinized by incubating them in xylene, rehydrated through graded alcohols, washed in phosphate-buffered saline, and stained in $1 \%$ Alcian blue solution (catalog number 26026-13; Electron Microscopy Sciences, Hatfield, PA) for 30 minutes. Nuclei were counterstained with $0.1 \%$ nuclear fast red (catalog number 26078-05; Electron Microscopy Sciences) for 5 minutes. Cytoseal XYL (catalog number 8312-4; Richard-Allan Scientific, Kalamazoo, MI) was used for coverslip mounting.

\section{IHC Analysis}

Sections were deparaffinized in xylene, rehydrated through graded alcohols, and washed in phosphate buffered saline. For p16 ${ }^{\text {Ink4a }}$, antigen retrieval was achieved by incubating in pepsin solution (catalog number AP9007005; Thermo Fisher Scientific) for 5 minutes. The other protein antigens were retrieved by microwaving sections in $10 \mathrm{mmol} / \mathrm{L}$ sodium citrate buffer (pH 6.0) for 20 minutes. For BrdU immunohistochemistry, sections were treated with $2 \mathrm{~N}$ hydrogen chloride for $20 \mathrm{mi}-$ nutes. Sections were treated with blocking buffer for 1 hour and then with a primary antibody overnight. Detailed antibody information and immunohistochemistry conditions are described in Table 1. After extensive washing in phosphate buffered saline, sections were incubated with Alexa Fluor 


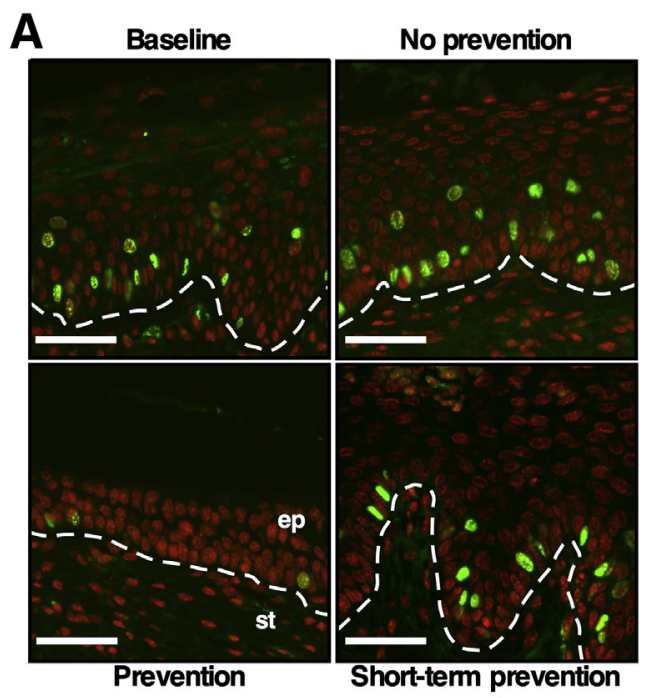

B

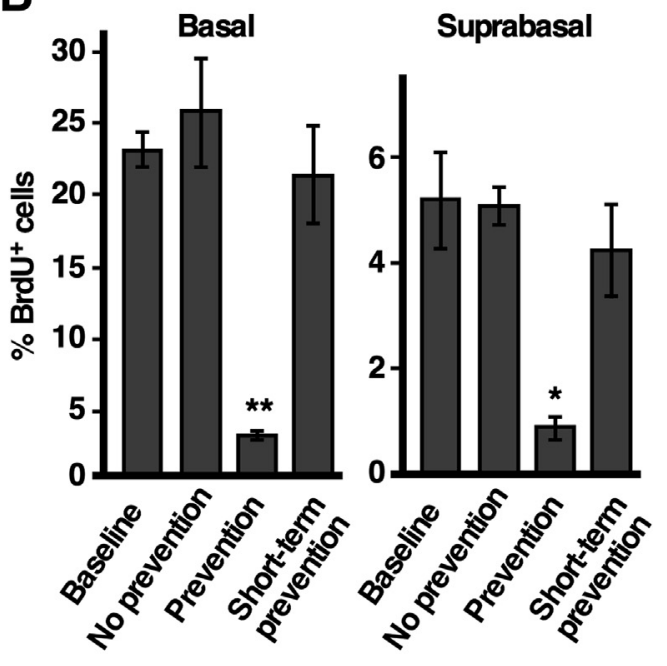

E
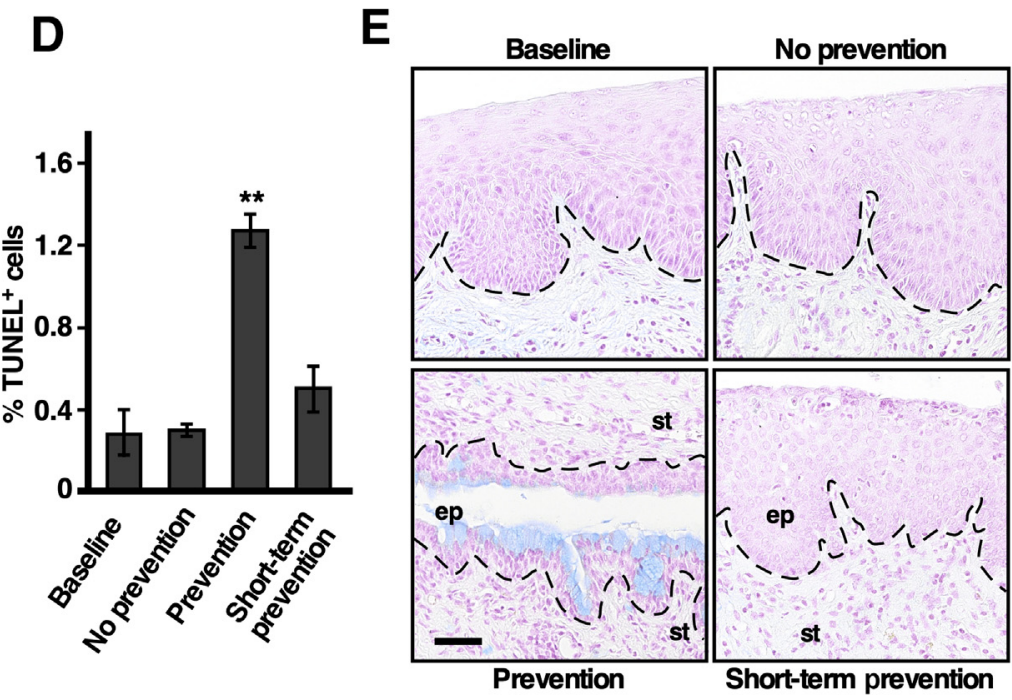

H

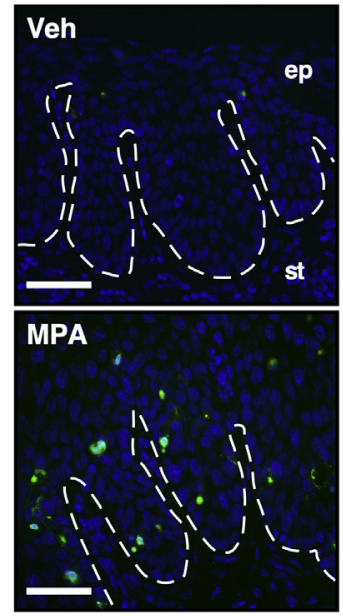

I

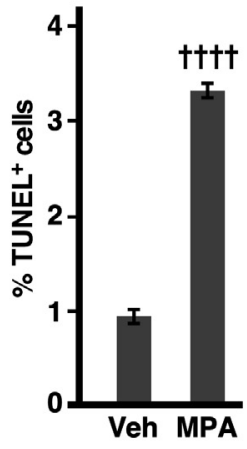


488-conjugated anti-rabbit IgG (catalog number A11008; Life Technologies, Carlsbad, CA) or anti-mouse IgG (catalog number A11001; Life Technologies). Sections were then incubated in Hoechst 33258 solution $(10 \mu \mathrm{g} / \mathrm{mL}$; catalog number B2883; Sigma-Aldrich) for 30 seconds to stain nuclei. Terminal deoxynucleotidyl transferase dUTP nick end labeling (TUNEL) assay was performed by using an ApopTaq Fluorescein in situ apoptosis detection kit according to the manufacturer's instructions (catalog number S7110; EMD Millipore, Burlington, MA). Slides were mounted using gelvatol mounting medium.

\section{Microscopy and Digital Image Analyses}

After staining, sections were visualized with an Eclipse Ti2 microscope (Nikon Instruments Inc., Melville, NY). Representative images were obtained with a Nikon DS-Qi2 monochrome CMOS camera or a DS-Ri2 color CMOS camera using Nikon NIS-Elements imaging software version 5.2. Cells positive for BrdU, Ki-67, and TUNEL were quantified with digital images from 3 to 5 random microscopic fields per tissue.

\section{Statistical Analysis}

MSTAT software version 6.4.2 (McArdle Laboratory for Cancer Research, Madison, WI; https://mcardle.wisc.edu/ mstat, last accessed April 23, 2019) was used to perform the one-sided Wilcoxon rank sum test (cervical neoplastic disease severity) and the Fisher exact test (disease incidence). For the comparisons of proliferation and apoptosis in two groups, a $t$-test was used. Web-based one-way analysis of variance testing was performed using VassarStats (http://vassarstats.net/anovalu.html, last accessed April 23, 2019) to evaluate proliferative and apoptotic indices in more than two groups. A $P \leq 0.05$ was considered to be statistically significant.

\section{Results}

\section{Effects of MPA on CIN Progression to Cervical Cancer}

To determine whether MPA is chemopreventive, HPVtg double transgenic mice were treated with $\mathrm{E}_{2}$ for 3 months and then divided into five treatment groups (Figure 1A). One group of mice was sacrificed immediately to determine the baseline disease state (baseline group; $n=7$ ). Another group of mice was treated with $\mathrm{E}_{2}$ for 3 additional months to determine the severity of cervical neoplastic disease without any chemopreventive treatment (no-prevention group; $n=$ 7). All mice in the baseline group had CIN lesions, but not cervical cancer (Table 2). All mice in the no-prevention group had cervical cancer and CIN lesions (Table 2). These results indicate that all mice had CIN before additional treatment and that continued $\mathrm{E}_{2}$ treatment promoted its progression to invasive cancer. These results were consistent with previously published results. ${ }^{30}$ The third group was treated with $\mathrm{E}_{2}$ plus MPA for 3 months (prevention group; $n$ $=6$ ). No mice in this group had cervical cancer, which was significantly different from the prevalence in the noprevention group $(P=0.001)$. In addition, five mice $(83.3 \%)$ did not have any cervical neoplastic disease. The epithelium in this group was also hypoplastic (Figure 1B). These results indicate that MPA not only prevented CIN from progressing to invasive cancer but also promoted regression of CIN lesions. It was determined whether MPA treatment for a shorter period had similar preventive effects. Two additional groups of mice were treated with $E_{2}$ for 3 months and then $\mathrm{E}_{2}$ plus MPA for 1 month (Figure 1A). One group of mice was sacrificed immediately (control group; $n$ $=10)$. Eight mice $(80 \%)$ did not have cervical neoplasia (Table 2); this rate was significantly lower than the prevalence of CIN in the baseline group $(P=0.002)$. The cervical epithelia were hypoplastic, similar to those in the prevention group (Figure 1B). These results indicate that 1-month treatment with MPA was sufficient to regress CIN lesions. The other group was treated with $\mathrm{E}_{2}$ for 2 additional months (short-term prevention group; $n=9$ ). Six mice had CIN lesions, and the remainder had cervical cancer (Table 2). The cervical epithelia were similar between the short-term prevention and no-prevention groups (Figure 1B). These results suggest that CIN lesions remaining after MPA treatment progressed to cervical cancer and that new CIN lesions developed. Nonetheless, the cancer prevalence was significantly lower in the short-term prevention group than in the no-prevention group $(P=0.01)$, indicating that MPA treatment for 1 month was partially preventive.

\footnotetext{
Figure 2 Medroxyprogesterone acetate (MPA) promotes cell phenotypes associated with anticancer activity. A: The proliferation index is reduced in the prevention group. Cervical sections were stained for bromodeoxyuridine (BrdU) (green). Nuclei were counterstained with Hoechst 33258 and pseudocolored red. B: Results shown in A were quantified. On average, 360 basal and 1062 suprabasal cells per sample were counted. A one-way analysis of variance test was performed followed by Tukey honestly significant difference (HSD) test. C: The apoptosis index is increased in the prevention group. Cervical sections were subjected to terminal deoxynucleotidyl transferase dUTP nick end labeling (TUNEL) assay. Arrowheads point to TUNEL ${ }^{+}$cells (green). Nuclei were stained with Hoechst 33258 and pseudocolored red. D: Results shown in C were quantified. On average, 1563 cells per sample were counted. A one-way analysis of variance test was performed followed by Tukey HSD test. E: Terminal differentiation is increased in the prevention group. Representative photomicrographs of Alcianblue-stained cervical sections are shown. F: The proliferation index has not changed after 16 hours of MPA treatment. Cervical sections were stained for the proliferation marker Ki-67 (green). Nuclei were counterstained with Hoechst 33258 and pseudocolored red. G: Results shown in $\mathbf{F}$ were quantified. On average, 271 basal and 807 suprabasal cells per sample were counted. H: The apoptosis index increases after 16 hours of MPA treatment. Cervical sections were subjected to TUNEL assay. TUNEL ${ }^{+}$cells are shown in green. Nuclei are stained with Hoechst 33258 (blue). I: Results shown in $\mathbf{H}$ were quantified. On average, 1475 cells per sample were counted. Dashed lines demarcate the border between the epithelium (ep) and stroma (st). Data are expressed as means \pm SEM. $n=3 .{ }^{*} P<0.05,{ }^{* *} P<0.01$ versus the other groups; ${ }^{\dagger \dagger \dagger} P<0.0001$ versus vehicle (2-tailed $t$-test). Scale bars $=50 \mu \mathrm{m}$. Veh, vehicle.
} 
A
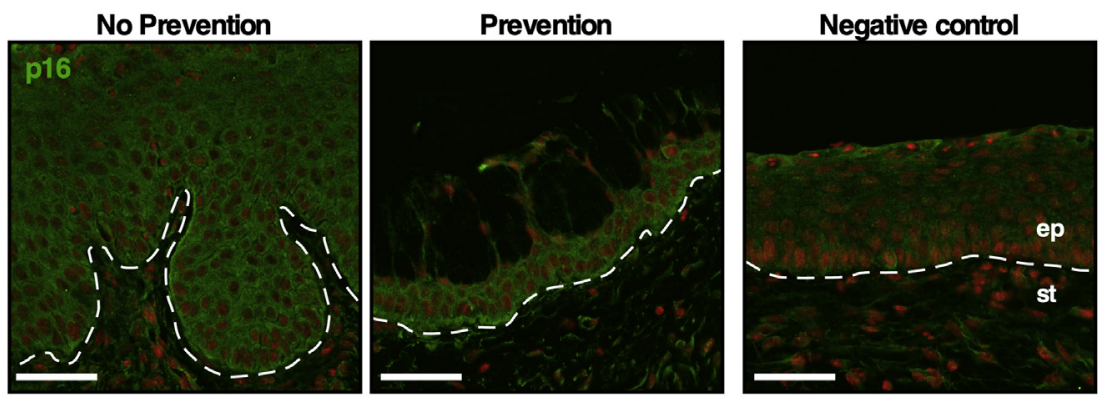

B
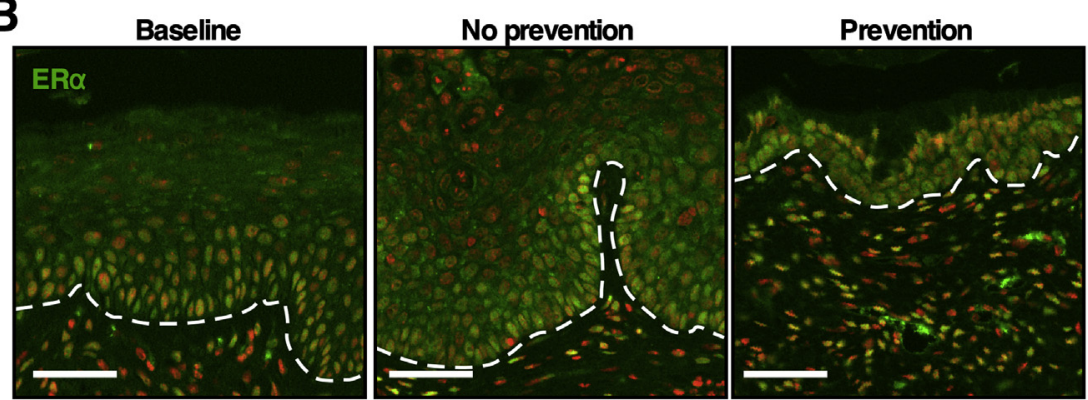

Short-term prevention

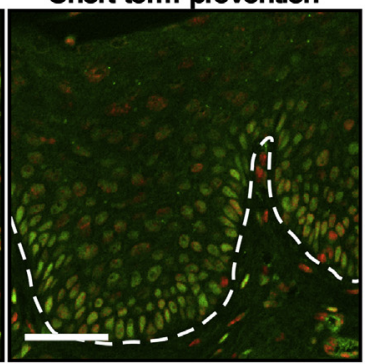

C

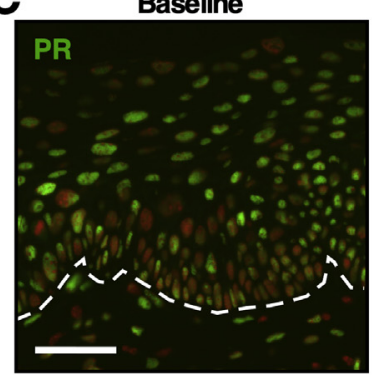

No prevention
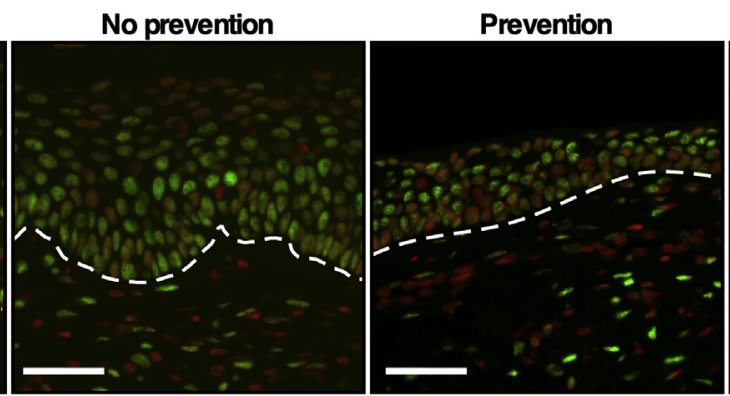

Short-term prevention
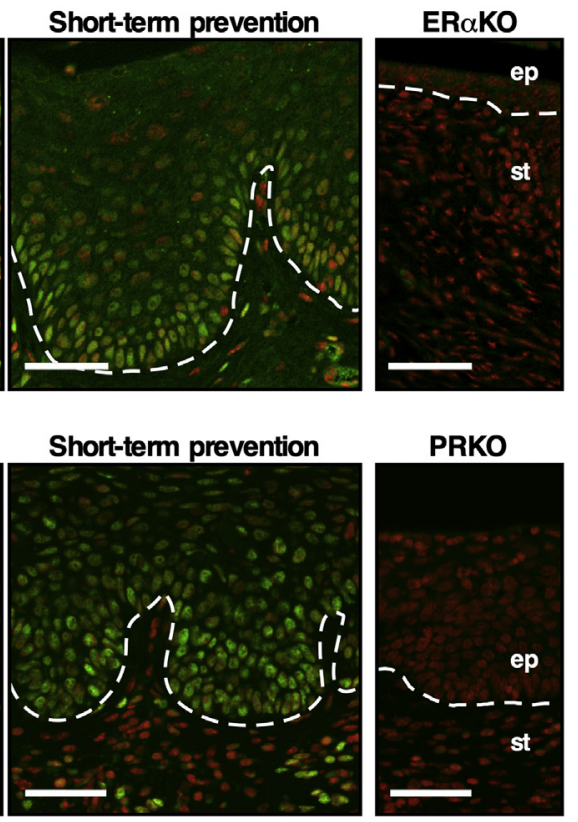

PRKO

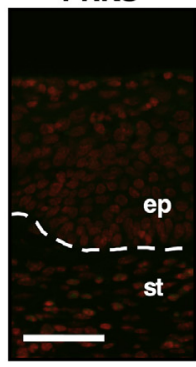

Figure 3 Biomarker expression is similar in all groups. A: Cervical sections were stained for $\mathrm{p} 16^{\text {Ink4a }}$ (green). Nuclei were stained with Hoechst 33258 and pseudocolored red. Nontransgenic mouse cervix was used as a negative control. B: Cervical sections were stained for estrogen receptor (ER)- $\alpha$ (green). Nuclei were stained with Hoechst 33258 and pseudocolored red. Cervical sections from Esr1 knockout mice (ER $\alpha$ KO) were used as a negative control. C: Cervical sections were stained for progesterone receptor (PR) (green). Nuclei were stained with Hoechst 33258 and pseudocolored red. Cervical sections from Pgr knockout mice (PRKO) were used as a negative control. Dashed lines demarcate the border between the epithelium (ep) and stroma (st). Scale bars $=50 \mu \mathrm{m}$.

\section{Effects of MPA on Cell Proliferation and Survival in the} Cervical Epithelium

To understand the mechanism of chemoprevention by MPA, cell proliferation and apoptotic indices in the cervical epithelium were measured by BrdU incorporation and TUNEL assay, respectively. In the prevention group that was treated with $\mathrm{E}_{2}$ plus MPA until the study end point, the percentages of $\mathrm{BrdU}^{+}$cells in the basal and suprabasal layers were significantly lower than those in the other groups (Figure 2, A and B). On the other hand, the percentage of $\mathrm{TUNEL}^{+}$cells was significantly higher compared to those in the other groups (Figure 2, C and D). In the short-term prevention group treated with $\mathrm{E}_{2}$ plus MPA for 1 month and then with $E_{2}$ alone for 2 months, the percentages of $\mathrm{BrdU}^{+}$and $\mathrm{TUNEL}^{+}$cells were similar to those in the no-prevention group that never received MPA (Figure 2, B and D). In addition, patches of epithelium in the prevention group stained positive with Alcian blue dye
(Figure 2E), indicating that the cells were terminally differentiated. Mice were also treated with MPA for 16 hours instead of 3 months; the cervical epithelia were similar in the MPA-treated and vehicle-treated mice (Supplemental Figure S1A). Consistently, the percentages of Ki- $67^{+}$proliferative cells were similar between the two groups (Figure 2, F and G). The percentage of TUNEL ${ }^{+}$ apoptotic cells, however, was significantly higher in MPAtreated mice than in the vehicle-treated control mice (Figure 2, $\mathrm{H}$ and I). These results suggest that MPA promotes cell death before inhibiting cell proliferation.

\section{Effects of MPA on Expression of Cervical Neoplastic Disease Biomarkers}

In HPV-negative cervical epithelia, minichromosome maintenance complex component 7 is expressed only in the basal layer, and $\mathrm{p} 16^{\text {Ink4a }}$ is rarely expressed (Figure $3 \mathrm{~A}$ and Supplemental Figure S1B). Their expression is 

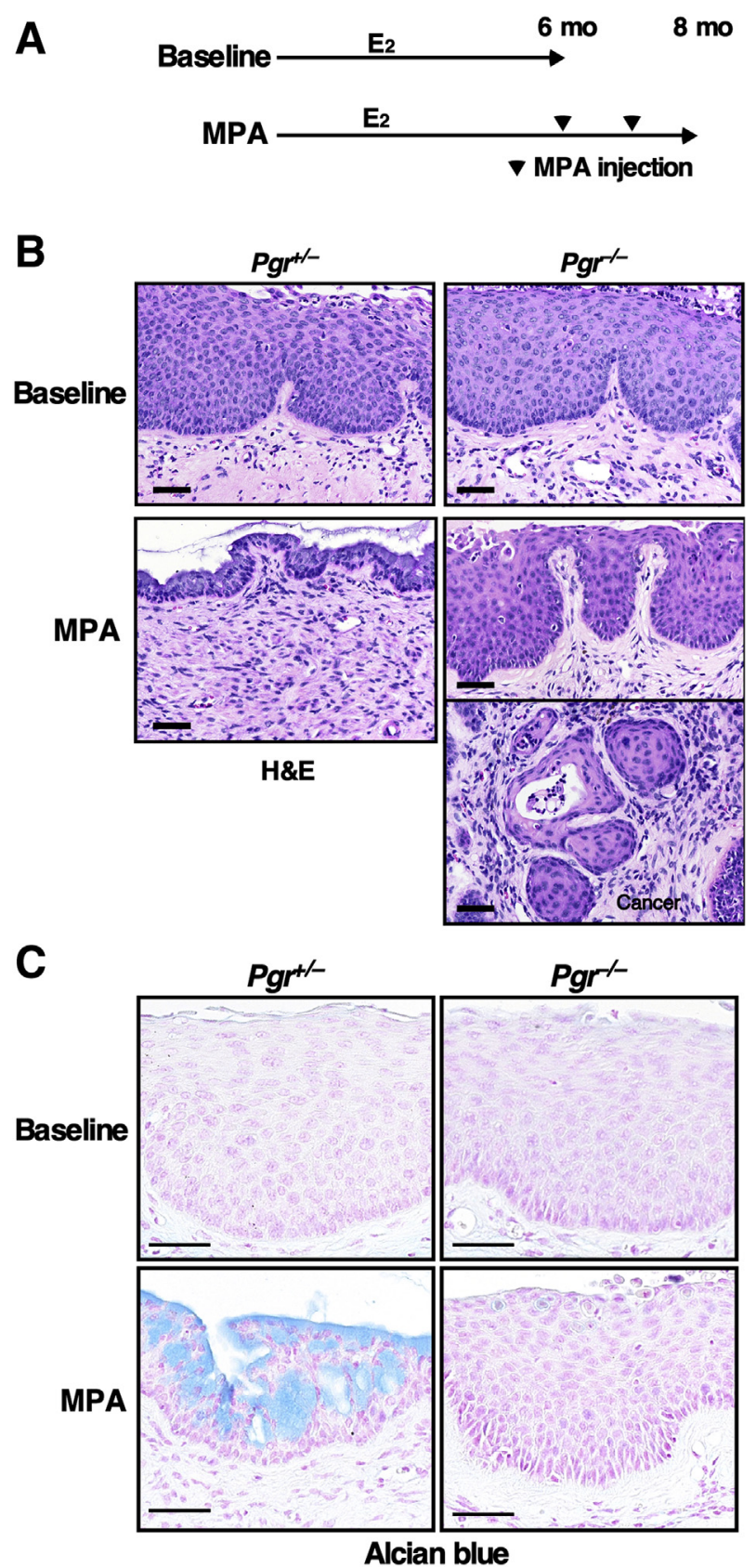

Figure 4 Progesterone receptor is required for cervical cancer prevention by medroxyprogesterone acetate (MPA). A: Treatment regimens are depicted. All mice were treated with estrogen $\left(E_{2}\right)$ until end points ( 6 or 8 months). Arrowheads indicate monthly injections with MPA. B: MPA induces hypoplasia only in Pgr-positive mice. Shown are highmagnification images of representative hematoxylin and eosin (H\&E)stained cervical epithelia from each genotype. C: Cervical sections were stained with Alcian blue. Nuclei were counterstained with nuclear fast red. Scale bars $=50 \mu \mathrm{m}$.

up-regulated in HPV-induced CIN and cervical cancer, mainly due to HPV E6 and E7. ${ }^{31,32}$ Expression levels of minichromosome maintenance complex component 7 and p16 $6^{\text {Ink4a }}$ were increased in mice treated with MPA for 16 hours or 3 months (ie, prevention group), similar to the finding in mice not treated with MPA (ie, no-prevention group) (Figure 3A and Supplemental Figure S1B). These results demonstrated that MPA did not inhibit the expression of E7 in the transgenic mice as shown previously. ${ }^{25} \mathrm{ER} \alpha$ is required for the development of cervical cancer. ${ }^{33}$ The expression levels of ER $\alpha$ in the cervical epithelium and stroma in the prevention group were similar to those in the other groups (Figure 3B). In immunohistochemistry analysis of PR, the expression of which depends on $\mathrm{ER} \alpha,{ }^{34}$ the PR-staining pattern was similar in all groups (Figure 3C). These results indicate that the preventive effect of MPA was not due to the inhibition of $E R \alpha$ expression or function.

\section{Effects of PR upon the Chemopreventive Effect of MPA}

Although MPA is synthetic progesterone, it activates not only PR but also other nuclear receptors such as glucocorticoid receptor, androgen receptor, and mineralocorticoid receptor. ${ }^{35}$ To determine whether PR is required for chemoprevention by MPA, HPVtg/Pgr ${ }^{+/-}$and HPVtg/ $\mathrm{Pgr}^{-I-}$ mice were treated with $\mathrm{E}_{2}$ for 6 months and each genotype was divided into 2 groups (Figure 4A). One group of mice was sacrificed immediately (baseline group). All mice of each genotype had CIN lesions, but not cervical cancer (Table 3), indicating that all mice had CIN before MPA treatment. This finding is consistent with previously published results from mice of a similar mixed genetic background. ${ }^{23}$ The cervical epithelia of $E_{2}$-treated $\mathrm{HPVtg} / \mathrm{Pgr}^{+/-}$and $\mathrm{HPVtg} / \mathrm{Pgr}^{-1-}$ mice were also similarly hyperplastic (Figure 4B). These results agree with the previous observation that $P g r$ genotype had no impact on the severity of cervical neoplasia when treated with $E_{2}$ only. ${ }^{25}$ Another group of mice was treated with $\mathrm{E}_{2}$ and MPA for 2 additional months (MPA group). As expected, cervical cancer did not develop in $\mathrm{HPVtg} / \mathrm{Pgr}^{+/-}$mice (Table 3). Strikingly, $47.1 \%$ of $H P V t g / P r^{-1-}$ mice in the MPA group $(n=17)$ had cervical cancer, indicating that CIN lesions had progressed. The cancer incidence was significantly higher than in the other groups $(P=0.003)$. $\mathrm{HPVtg} / \mathrm{Pgr}^{+/-}$mice that were treated with $\mathrm{E}_{2}$ plus MPA displayed hypoplastic epithelia (Figure 4B). On the other hand, $\mathrm{HPVtg} / \mathrm{Pgr}^{-1-}$ mice that were treated identically had dysplastic and hyperplastic epithelia as well as cancer (Figure 4B). The cervical epithelia of MPA-treated HPVtg/ $\mathrm{Pgr}^{+/-}$mice, but not of $\mathrm{HPVtg} / \mathrm{Pgr}^{-/-}$mice, stained positive for Alcian blue (Figure $4 \mathrm{C}$ ). These results demonstrate that PR is necessary for MPA to prevent cervical cancer. Interestingly, one $\mathrm{HPVtg} / \mathrm{Pgr}^{-1-}$ mouse that was treated with MPA did not have cervical neoplasia and had a hypoplastic epithelium similar to that in identically treated $\mathrm{HPVtg}_{\mathrm{Pgr}}{ }^{+-}$mice (Table 3 and Supplemental Figure S2A). We confirmed that PR was not expressed in the cervix of that mouse, consistent with its genotype (Supplemental Figure S2B). 
Table 3 Summary of Worst Diseases of the Cervix in Pgr-Deficient Mice

\begin{tabular}{lllllllll}
\hline & & & \multicolumn{2}{c}{ Dysplasia only, $n$} & & \\
Genotype & Treatment group & Group size, $n$ & No disease, $n$ & CIN1 & CIN2 & CIN3 & Cancer and dysplasia, $n$ & Cancer incidence, \% \\
\hline HPVtg/Pgr & Control & 6 & 0 & 1 & 4 & 1 & 0 & 0 \\
HPVtg/Pgr & MPA & 15 & 6 & 6 & 3 & 0 & 0 & 0 \\
& Control & 4 & 0 & 2 & 2 & 0 & 0 & 0 \\
& MPA & 17 & 1 & 4 & 3 & 1 & 8 & $47.1^{*}$ \\
\hline
\end{tabular}

For Wilcoxon rank sum test, each lesion was given following arbitrary score: no disease $=1 ;$ CIN1 $=2 ;$ CIN2 $=3$; CIN3 $=4$; and cancer $=5$.

${ }^{*} P<0.01$ versus the other groups (two-sided Fisher exact test).

CIN, cervical intraepithelial neoplasia; MPA, medroxyprogesterone acetate.

\section{Discussion}

Cervical cancer can be prevented by HPV vaccinations (primary prevention) and Pap tests (secondary prevention). The latter detects precancerous lesions (ie, CINs), and they are treated to prevent cervical cancer. There has been little effort toward developing new treatments for CINs because available surgical procedures are effective in removing CIN lesions. Current invasive therapy, however, increases the risk for complications such as preterm birth and infant mortality in future pregnancies. ${ }^{36}$ It is an important issue because the incidence of CINs is highest among women between 20 and 40 years of age. ${ }^{37,38}$ The development of a noninvasive and effective treatment for CINs is warranted. Here, evidence was provided showing that MPA is effective in treating CIN lesions-that is, chemopreventive for cervical cancer. Cervical cancer was absent in the prevention group that was treated with MPA for the last 3 months of 6month $\mathrm{E}_{2}$ treatment (Table 2). This preventive effect was mediated by inducing apoptosis and terminal differentiation and by inhibiting cell proliferation (Figure 2). CIN was regressed with MPA treatment for 1 month, but cervical neoplastic diseases developed again (Table 2).

It can be argued that MPA treatment should be continued. However, unlike women with HPV, in whom only a small fraction of cervical epithelium is infected with HPV, the transgenic mice express E6 and E7 viral oncoproteins in all cervical epithelial cells. Therefore, in women, CIN would not recur unless a woman were reinfected with the virus. If these findings are translatable, we propose that MPA treatment should be continued until the host immune system clears the HPV infection.

MPA is commonly used as an injectable contraceptive. Although the dosing used in this study was higher than the contraceptive dose, it falls within the range of dosing used in a clinical trial in endometrial cancer. ${ }^{39}$ The ER $\alpha$ degrader fulvestrant has been reported to be chemopreventive of cervical cancer in the same mouse model. ${ }^{30}$ MPA would be a better choice because fulvestrant causes menopausal symptoms and is much less tolerable in premenopausal women. ${ }^{40}$ In addition, MPA is much less expensive and can be stored at room temperature. One potential concern is that MPA induces cervical epithelium atrophy (Figure 1B). Fortunately, cervical/vaginal atrophy has not been reported in endometrial cancer patients who have received MPA therapy. In addition, it has been shown that treatment with estrogen plus MPA relieves vaginal atrophy in postmenopausal women. ${ }^{41,42}$ Nonetheless, it remains to be determined whether MPA induces cervical/vaginal atrophy in premenopausal women, the group at greatest risk for cervical cancer.

A total of $47.1 \%$ of MPA-treated $\mathrm{HPVtg} / \mathrm{Pgr}^{-1-}$ mice developed cervical cancer (Table 3). This observation suggests that PR is the major mediator of MPA-mediated chemoprevention of cervical cancer. Because MPA is a PR agonist, we postulate that MPA prevents cervical cancer by up-regulating PR target genes. Although PR target genes have not been extensively characterized in cervical tissues, up-regulation of Hand 2 by PR is required for progesterone-mediated suppression of epithelial cell proliferation in the mouse uterus. ${ }^{43}$ It is conceivable that endogenous progesterone has a preventive effect on cervical cancer through PR. This idea may seem contradictory to observations showing that the severity levels of cervical neoplastic disease are similar between PR-positive and PRdeficient HPV transgenic mice (Table 3). ${ }^{25}$ However, longterm treatment with $\mathrm{E}_{2}$ keeps mice in a continuous estruslike state, in which endogenous progesterone levels are lowest. ${ }^{19,44}$ Endogenous progesterone would prevent cervical cancer when it surges during the luteal phase. ${ }^{45}$ Under this condition, the loss of PR would promote cervical carcinogenesis. In this regard, PR is expressed in only $20 \%$ to $40 \%$ of human cervical cancers. ${ }^{46-49}$ More importantly, although it remains to be confirmed in independent studies, it is less likely that PR-positive CIN3 progresses to invasive cancer. ${ }^{50}$ These data should be interpreted with caution because the menstrual cycle stage of study subjects was not determined and because it remains to be determined whether PR expression changes during the hormonal cycle. In the mouse cervix, $\mathrm{E}_{2}$ up-regulates PR through $\mathrm{ER} \alpha{ }^{34}$

It is possible that some PR-positive CIN lesions are resistant to MPA because CIN lesions remained in some $P g r$-positive mice after MPA treatment (Tables 2 and 3). Supporting this, PR-positive recurrent cervical cancer does not respond to MPA in the HPV transgenic mouse model. ${ }^{51}$ Some PR-positive endometrial cancers do not respond to MPA therapy. ${ }^{39,52}$ These observations suggest that, in addition to PR, other factors are required for the maximum 
anticancer activity of MPA. It is intriguing that one HPVtg/ $\mathrm{Pgr}^{-/-}$mouse treated with MPA had a hypoplastic epithelium without any cervical neoplastic disease (Figure 4B and Supplemental Figure S2A). Some PR-negative endometrial cancers respond to MPA therapy. ${ }^{39,52}$ These observations suggest that MPA may be useful in preventing cervical cancer through a PR-independent mechanism under conditions yet to be determined. In this regard, MPA binds and activates other nuclear receptors including glucocorticoid receptor and androgen receptor. ${ }^{35}$ High glucocorticoid receptor expression has been associated with a better prognosis in cervical cancer. ${ }^{53}$ Androgen receptor expression decreases as cervical neoplastic disease progresses, and knockdown of androgen receptor increases the invasion of cervical cancer cells in vivo. ${ }^{54,55}$

In summary, these results indicate that MPA is efficient in preventing the development of cervical cancer from PRpositive CIN lesions. MPA is affordable and does not require special skills or instruments for administration. These findings provide a biomarker (ie, PR) for patient selection in a clinical trial. Gynecologic health (eg, cervical/ vaginal atrophy) should be evaluated during a trial. If the treatment is proven effective, it will improve not only the physical health of women but also their psychological and psychosocial wellness on a global scale.

\section{Acknowledgments}

We thank Drs. Roger Price and David Stewart for consultation on histopathology and critically reading the manuscript, respectively.

S.B. and S.-H.C. conceived and designed the study and wrote and revised the manuscript; S.B., F.F.M., and S.-H.C. developed the methodology and analyzed the data; S.-H.C. supervised the study.

\section{Supplemental Data}

Supplemental material for this article can be found at http://doi.org/10.1016/j.ajpath.2019.08.013.

\section{References}

1. Steenbergen RD, Snijders PJ, Heideman DA, Meijer CJ: Clinical implications of (epi)genetic changes in HPV-induced cervical precancerous lesions. Nat Rev Cancer 2014, 14:395-405

2. Ferlay J, Colombet M, Soerjomataram I, Mathers C, Parkin DM, Pineros M, Znaor A, Bray F: Estimating the global cancer incidence and mortality in 2018: GLOBOCAN sources and methods. Int J Cancer 2019, 144:1941-1953

3. Bell S, Porter M, Kitchener H, Fraser C, Fisher P, Mann E: Psychological response to cervical screening. Prev Med 1995, 24: 610-616

4. Gray NM, Sharp L, Cotton SC, Masson LF, Little J, Walker LG, Avis M, Philips Z, Russell I, Whynes D, Cruickshank M, Woolley CM; TOMBOLA group: Psychological effects of a low-grade abnormal cervical smear test result: anxiety and associated factors. Br J Cancer 2006, 94:1253-1262

5. Lerman C, Miller SM, Scarborough R, Hanjani P, Nolte S, Smith D: Adverse psychologic consequences of positive cytologic cervical screening. Am J Obstet Gynecol 1991, 165:658-662

6. McDonald TW, Neutens JJ, Fischer LM, Jessee D: Impact of cervical intraepithelial neoplasia diagnosis and treatment on self-esteem and body image. Gynecol Oncol 1989, 34:345-349

7. Roden RB, Stern PL: Opportunities and challenges for human papillomavirus vaccination in cancer. Nat Rev Cancer 2018, 18: 240-254

8. Ferlay J, Soerjomataram I, Dikshit R, Eser S, Mathers C, Rebelo M, Parkin DM, Forman D, Bray F: Cancer incidence and mortality worldwide: sources, methods and major patterns in GLOBOCAN 2012. Int J Cancer 2015, 136:E359-E386

9. Castle PE, Rodriguez AC, Burk RD, Herrero R, Wacholder S, Alfaro M, Morales J, Guillen D, Sherman ME, Solomon D, Schiffman M: Short term persistence of human papillomavirus and risk of cervical precancer and cancer: population based cohort study. BMJ 2009, 339:b2569

10. McCredie MR, Sharples KJ, Paul C, Baranyai J, Medley G, Jones RW, Skegg DC: Natural history of cervical neoplasia and risk of invasive cancer in women with cervical intraepithelial neoplasia 3 : a retrospective cohort study. Lancet Oncol 2008, 9:425-434

11. Moreno V, Bosch FX, Munoz N, Meijer CJ, Shah KV, Walboomers JM, Herrero R, Franceschi S: Effect of oral contraceptives on risk of cervical cancer in women with human papillomavirus infection: the IARC multicentric case-control study. Lancet 2002, 359:1085-1092

12. Munoz N, Franceschi S, Bosetti C, Moreno V, Herrero R, Smith JS, Shah KV, Meijer CJ, Bosch FX: Role of parity and human papillomavirus in cervical cancer: the IARC multicentric case-control study. Lancet 2002, 359:1093-1101

13. Weikum ER, Liu X, Ortlund EA: The nuclear receptor superfamily: a structural perspective. Protein Sci 2018, 27:1876-1892

14. Hoover RN, Hyer M, Pfeiffer RM, Adam E, Bond B, Cheville AL, Colton T, Hartge P, Hatch EE, Herbst AL, Karlan BY, Kaufman R, Noller KL, Palmer JR, Robboy SJ, Saal RC, Strohsnitter W, TitusErnstoff L, Troisi R: Adverse health outcomes in women exposed in utero to diethylstilbestrol. N Engl J Med 2011, 365:1304-1314

15. Hsieh CJ, Hong MK, Chen PC, Wang JH, Chu TY: Antiestrogen use reduces risk of cervical neoplasia in breast cancer patients: a population-based study. Oncotarget 2017, 8:29361-29369

16. Harris TG, Miller L, Kulasingam SL, Feng Q, Kiviat NB, Schwartz SM, Koutsky LA: Depot-medroxyprogesterone acetate and combined oral contraceptive use and cervical neoplasia among women with oncogenic human papillomavirus infection. Am J Obstet Gynecol 2009, 200:489.e1-489.e8

17. Arbeit JM, Howley PM, Hanahan D: Chronic estrogen-induced cervical and vaginal squamous carcinogenesis in human papillomavirus type 16 transgenic mice. Proc Natl Acad Sci U S A 1996, 93: 2930-2935

18. Elson DA, Riley RR, Lacey A, Thordarson G, Talamantes FJ, Arbeit JM: Sensitivity of the cervical transformation zone to estrogeninduced squamous carcinogenesis. Cancer Res 2000, 60:1267-1275

19. Riley RR, Duensing S, Brake T, Munger K, Lambert PF, Arbeit JM: Dissection of human papillomavirus E6 and E7 function in transgenic mouse models of cervical carcinogenesis. Cancer Res 2003, 63: $4862-4871$

20. Brake T, Connor JP, Petereit DG, Lambert PF: Comparative analysis of cervical cancer in women and in a human papillomavirustransgenic mouse model: identification of minichromosome maintenance protein 7 as an informative biomarker for human cervical cancer. Cancer Res 2003, 63:8173-8180

21. Shin MK, Balsitis S, Brake T, Lambert PF: Human papillomavirus E7 oncoprotein overrides the tumor suppressor activity of p21Cip1 in cervical carcinogenesis. Cancer Res 2009, 69:5656-5663 
22. den Boon JA, Pyeon D, Wang SS, Horswill M, Schiffman M, Sherman M, Zuna RE, Wang Z, Hewitt SM, Pearson R, Schott M, Chung L, He Q, Lambert P, Walker J, Newton MA, Wentzensen N, Ahlquist P: Molecular transitions from papillomavirus infection to cervical precancer and cancer: role of stromal estrogen receptor signaling. Proc Natl Acad Sci U S A 2015, 112:E3255-E3264

23. Chung SH, Shin MK, Korach KS, Lambert PF: Requirement for stromal estrogen receptor alpha in cervical neoplasia. Horm Cancer 2013, 4:50-59

24. Son J, Park Y, Chung SH: Epithelial oestrogen receptor alpha is dispensable for the development of oestrogen-induced cervical neoplastic diseases. J Pathol 2018, 245:147-152

25. Yoo YA, Son J, Mehta FF, DeMayo FJ, Lydon JP, Chung SH: Progesterone signaling inhibits cervical carcinogenesis in mice. Am J Pathol 2013, 183:1679-1687

26. Herber R, Liem A, Pitot H, Lambert PF: Squamous epithelial hyperplasia and carcinoma in mice transgenic for the human papillomavirus type 16 E7 oncogene. J Virol 1996, 70:1873-1881

27. Song S, Pitot HC, Lambert PF: The human papillomavirus type 16 E6 gene alone is sufficient to induce carcinomas in transgenic animals. J Virol 1999, 73:5887-5893

28. Fernandez-Valdivia R, Jeong J, Mukherjee A, Soyal SM, Li J, Ying Y, Demayo FJ, Lydon JP: A mouse model to dissect progesterone signaling in the female reproductive tract and mammary gland. Genesis 2010, 48:106-113

29. Hayashi S, Lewis P, Pevny L, McMahon AP: Efficient gene modulation in mouse epiblast using a Sox2Cre transgenic mouse strain. Gene Expr Patterns 2002, 2:93-97

30. Chung SH, Lambert PF: Prevention and treatment of cervical cancer in mice using estrogen receptor antagonists. Proc Natl Acad Sci U S A 2009, 106:19467-19472

31. Balsitis S, Dick F, Dyson N, Lambert PF: Critical roles for non-pRb targets of human papillomavirus type 16 E7 in cervical carcinogenesis. Cancer Res 2006, 66:9393-9400

32. Shai A, Brake T, Somoza C, Lambert PF: The human papillomavirus E6 oncogene dysregulates the cell cycle and contributes to cervical carcinogenesis through two independent activities. Cancer Res 2007, $67: 1626-1635$

33. Chung SH, Wiedmeyer K, Shai A, Korach KS, Lambert PF: Requirement for estrogen receptor alpha in a mouse model for human papillomavirus-associated cervical cancer. Cancer Res 2008, 68: 9928-9934

34. Mehta FF, Son J, Hewitt SC, Jang E, Lydon JP, Korach KS, Chung SH: Distinct functions and regulation of epithelial progesterone receptor in the mouse cervix, vagina, and uterus. Oncotarget 2016, 7:17455-17467

35. Selman PJ, Wolfswinkel J, Mol JA: Binding specificity of medroxyprogesterone acetate and proligestone for the progesterone and glucocorticoid receptor in the dog. Steroids 1996, 61:133-137

36. Arbyn M, Kyrgiou M, Simoens C, Raifu AO, Koliopoulos G, MartinHirsch P, Prendiville W, Paraskevaidis E: Perinatal mortality and other severe adverse pregnancy outcomes associated with treatment of cervical intraepithelial neoplasia: meta-analysis. BMJ 2008, 337: a1284

37. Henk HJ, Insinga RP, Singhal PK, Darkow T: Incidence and costs of cervical intraepithelial neoplasia in a US commercially insured population. J Low Genit Tract Dis 2010, 14:29-36

38. Orumaa M, Leinonen MK, Campbell S, Moller B, Myklebust TA, Nygård M: Recent increase in incidence of cervical precancerous lesions in Norway: nationwide study from 1992 to 2016. Int J Cancer 2019, 145:2629-2638
39. Thigpen JT, Brady MF, Alvarez RD, Adelson MD, Homesley HD, Manetta A, Soper JT, Given FT: Oral medroxyprogesterone acetate in the treatment of advanced or recurrent endometrial carcinoma: a doseresponse study by the Gynecologic Oncology Group. J Clin Oncol 1999, 17:1736-1744

40. Hirsch HD, Shih E, Thacker HL: ERAAs for menopause treatment: welcome the 'designer estrogens'. Cleve Clin J Med 2017, 84: 463-470

41. Tan D, Haines CJ, Limpaphayom KK, Holinka CF, Ausmanas MK: Relief of vasomotor symptoms and vaginal atrophy with three doses of conjugated estrogens and medroxyprogesterone acetate in postmenopausal Asian women from 11 countries: the Pan-Asia menopause (PAM) study. Maturitas 2005, 52:35-51

42. Utian WH, Shoupe D, Bachmann G, Pinkerton JV, Pickar JH: Relief of vasomotor symptoms and vaginal atrophy with lower doses of conjugated equine estrogens and medroxyprogesterone acetate. Fertil Steril 2001, 75:1065-1079

43. Li Q, Kannan A, DeMayo FJ, Lydon JP, Cooke PS, Yamagishi H, Srivastava D, Bagchi MK, Bagchi IC: The antiproliferative action of progesterone in uterine epithelium is mediated by Hand2. Science 2011, 331:912-916

44. Wood GA, Fata JE, Watson KL, Khokha R: Circulating hormones and estrous stage predict cellular and stromal remodeling in murine uterus. Reproduction 2007, 133:1035-1044

45. Chung SH: Targeting female hormone receptors as cervical cancer therapy. Trends Endocrinol Metab 2015, 26:399-401

46. Suzuki Y, Nakano T, Arai T, Morita S, Tsujii H, Oka K: Progesterone receptor is a favorable prognostic factor of radiation therapy for adenocarcinoma of the uterine cervix. Int J Radiat Oncol Biol Phys 2000, 47:1229-1234

47. Ford LC, Berek JS, Lagasse LD, Hacker NF, Heins YL, DeLange RJ: Estrogen and progesterone receptor sites in malignancies of the uterine cervix, vagina, and vulva. Gynecol Oncol 1983, 15:27-31

48. Fujiwara H, Tortolero-Luna G, Mitchell MF, Koulos JP, Wright TC Jr: Adenocarcinoma of the cervix. Expression and clinical significance of estrogen and progesterone receptors. Cancer 1997, 79:505-512

49. Kwasniewska A, Postawski K, Gozdzicka-Jozefiak A, Kwasniewski W, Grywalska E, Zdunek M, Korobowicz E: Estrogen and progesterone receptor expression in HPV-positive and HPVnegative cervical carcinomas. Oncol Rep 2011, 26:153-160

50. Fonseca-Moutinho JA, Cruz E, Carvalho L, Prazeres HJ, de Lacerda MM, da Silva DP, Mota F, de Oliveira CF: Estrogen receptor, progesterone receptor, and bcl-2 are markers with prognostic significance in CIN III. Int J Gynecol Cancer 2004, 14:911-920

51. Mehta FF, Baik S, Chung SH: Recurrence of cervical cancer and its resistance to progestin therapy in a mouse model. Oncotarget 2017, 8: $2372-2380$

52. Ehrlich CE, Young PC, Stehman FB, Sutton GP, Alford WM: Steroid receptors and clinical outcome in patients with adenocarcinoma of the endometrium. Am J Obstet Gynecol 1988, 158:796-807

53. Kost BP, Beyer S, Schroder L, Zhou J, Mayr D, Kuhn C, Schulze S, Hofmann S, Mahner S, Jeschke U, Heidegger H: Glucocorticoid receptor in cervical cancer: an immunohistochemical analysis. Arch Gynecol Obstet 2019, 299:203-209

54. Noel JC, Bucella D, Fayt I, Simonart T, Buxant F, Anaf V, Simon P: Androgen receptor expression in cervical intraepithelial neoplasia and invasive squamous cell carcinoma of the cervix. Int J Gynecol Pathol 2008, 27:437-441

55. Zhai Y, Bommer GT, Feng Y, Wiese AB, Fearon ER, Cho KR: Loss of estrogen receptor 1 enhances cervical cancer invasion. Am J Pathol 2010, 177:884-895 